\title{
Accelerating caregivers' HIV status disclosure to community-based lay social welfare volunteers in Tanzania
}

\author{
Amon Exavery ${ }^{1 *} \mathbb{D}$, John Charles ${ }^{1}$, Asheri Barankena ${ }^{1}$, Erica Kuhlik², Godfrey Martin Mubyazi ${ }^{3}$, Christina Kyaruzi $^{1}$, \\ Tumainiel Mbwambo ${ }^{1}$, Amal Ally' ${ }^{1}$ Remmy Mseya ${ }^{1}$, Levina Kikoyo ${ }^{1}$ and Elizabeth Jere ${ }^{1}$
}

\begin{abstract}
Background: HIV status disclosure facilitates access to HIV-related prevention and treatment services and increases opportunities for social support, HIV risk reduction with partners, and index testing for sexual partners or children. This study assessed the effect of a program model of community-based social welfare volunteers on HIV status disclosure among caregivers of orphans and vulnerable children (OVC).

Methods: This was a longitudinal study, which was based on OVC caregivers who were beneficiaries of the USAID Kizazi Kipya project in Tanzania. They were enrolled (baseline) by community social welfare volunteers during 20172018, received services, and reassessed at midline in 2019. Caregivers who reported having been HIV tested, were asked to voluntarily report the status in order for the volunteers to establish and provide needed services. Those who reported their HIV status as negative or positive were grouped as "disclosed", and those who knew their status but did not report it were documented as "undisclosed". McNemar's tests compared disclosure rates at baseline and midline. Multivariable analysis was conducted using generalized estimating equation (GEE).
\end{abstract}

Results: The study analyzed 140,664 caregivers (72\% female) from 81 district councils of Tanzania. Their mean age at enrollment was 47.4 years. Overall, $81.3 \%$ of the caregivers disclosed their HIV status to the project staff at baseline; this increased significantly to $96.1 \%$ at midline $(p<0.001)$. Disclosure at baseline varied significantly by sociodemographic characteristic $(p<0.05)$, with higher disclosure in females, among urban residents, and higher educated caregivers. However, the observed disclosure variations by sociodemographic characteristics at baseline disappeared at midline and disclosure reached around $96 \%$ across the characteristics $(p>0.05)$. In the multivariable analysis, caregivers' likelihood of HIV status disclosure was nearly 6 times higher at midline than at baseline, when baseline characteristics were adjusted for $(\mathrm{OR}=5.76,95 \% \mathrm{Cl} 5.59-5.94, p<0.001)$. There were 26,329 caregivers who did not disclose their HIV status at baseline (i.e., $0 \%$ diclosure rate at baseline), but $94.7 \%(n=24,933)$ had disclosed by midline, and their disclosure trend was rapidly increasing as their duration of exposure to the project increased.

Conclusions: This study detected an increased caregivers' HIV status disclosure to the USAID Kizazi Kipya project staff by $14.8 \%$, from $81.3 \%$ at baseline to $96.1 \%$ at midline within an average project exposure period of 1.4 years. The observed loss of sociodemographic differences in HIV status disclosure rate at midline implies that community-based interventions may be well-positioned to successfully address and eliminate sociodemographic barriers to service uptake and consequently improve services coverage and health outcomes.

\footnotetext{
*Correspondence: aexavery@pactworld.org

1 Pact, P.O. Box 6348, Dar es Salaam, Tanzania

Full list of author information is available at the end of the article
}

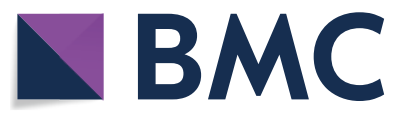

(c) The Author(s) 2021. This article is licensed under a Creative Commons Attribution 4.0 International License, which permits use, sharing, adaptation, distribution and reproduction in any medium or format, as long as you give appropriate credit to the original author(s) and the source, provide a link to the Creative Commons licence, and indicate if changes were made. The images or other third party material in this article are included in the article's Creative Commons licence, unless indicated otherwise in a credit line to the material. If material is not included in the article's Creative Commons licence and your intended use is not permitted by statutory regulation or exceeds the permitted use, you will need to obtain permission directly from the copyright holder. To view a copy of this licence, visit http://creativeco mmons.org/licenses/by/4.0/. The Creative Commons Public Domain Dedication waiver (http://creativecommons.org/publicdomain/ zero/1.0/) applies to the data made available in this article, unless otherwise stated in a credit line to the data. 
Keyword: HIV status, Disclosure, Caregivers of orphans and vulnerable children, Volunteers, Kizazi Kipya, Tanzania

\section{Background}

HIV status disclosure facilitates entry into care and treatments programs. This is a key public health strategy for HIV prevention and control [1-3]. It has been observed that HIV status disclosure motivates sexual partners to seek HIV testing and change sexual practices and behaviours, which ultimately declines HIV transmission [3]. Disclosure is encouraged to reduce sexual risk behaviours, HIV transmission, and HIV-associated stigma [4, 5]. At an individual level, disclosure improves opportunities for social support, access to care and treatment services, as well as planning for the future [3].

Extant statistics of HIV status disclosure among sexual partners are diverse [6-8], and tends to show better rates in developed than developing countries [9]. Within Tanzania, disclosure rates vary by geography [10-12]. A recent study in Kilimanjaro found that HIV serostatus disclosure to partners was 66\% [13], and ranged from 93.3\% in Mwanza [14], to 28\% in Morogoro [15]. One study in three government-owned health facilities in Pwani region of Tanzania, found that nurse-facilitated HIV status disclosure was only $39 \%$ among postpartum women who had not yet disclosed [16]. These variations highlight a need for further research to uncover factors encouraging HIV status disclosure, and interventions to address disclosure barriers.

Previous studies identified several factors associated with HIV status disclosure: stigma and discrimination [17-19], economic status [20, 21], literacy [22], gender [9], age [23-25], marital status [13, 23-25], being on ART, contraceptive use [13], knowledge of partner's HIV status, membership in HIV/AIDS control associations [26], and many others [14, 15, 27-30]. In these studies, disclosure has mainly been that of: revealing one's own HIV test results to a sexual partner, family members or friends [12, 13, 23, 31-36]; and HIV-infected children learning their status from their parents, guardians or caregivers [37-40].

Despite this evidence, little is known about HIV status disclosure to HIV prevention and treatment programs. Documented evidence of interventions enhancing HIV status disclosure is also rare. Some community-based HIV prevention and treatment programs promote voluntary disclosure of one's HIV status in order to establish needed services. Therefore, undisclosed status, limits what the programs can achieve with respect to provision of HIV services targeted to the beneficiary's unique HIV needs [41]. This highlights the need for interventions to support voluntary HIV status disclosure among individuals for health and social needs identification and timely provision of such services.

This study assessed the contribution of the USAID Kizazi Kipya project's model of community-based service delivery using volunteers on HIV status disclosure rates among caregivers of orphans and vulnerable children (OVC) in Tanzania by comparing baseline and midline disclosure rates. The program, USAID Kizazi Kipya, scales-up service uptake among HIV infected or affected OVC and their caregivers. Therefore, this study was appropriate in this population because the population is already at high risk of and burdened by HIV. For example, early enrollee caregivers in this project had a self-reported HIV prevalence of $28.3 \%$ [42].

\section{Methods \\ Data source}

Data for this study are from a community-based project in Tanzania known as USAID Kizazi Kipya. The project (2016-2021) aims at scaling up the uptake of HIV, health, and social services by OVC and their caregivers. The data were collected by Lead Case Workers (LCWs) and Community Case Workers (CCWs) during beneficiary screening and enrollment using the project's screening and enrollment, and Family and Child Asset Assessment (FCAA) tools. LCWs and CCWs are lay social welfare volunteers recruited by a government standard and trained in basic social welfare case management skills. Beneficiaries were enrolled into the USAID Kizazi Kipya project if their household met one or more of the enrollment criteria. The criteria refer to 14 household vulnerabilities related to HIV, one of which is whether one or more household members are HIV positive. The criteria are published [41].

\section{Services provided by the USAID Kizazi Kipya project to OVC caregivers}

While the USAID Kizazi Kipya project serves both OVC and their caregivers, for the purpose of this study, only services provided to the caregivers are described (Table 1). The project works with LCWs and CCWs at the community level to provide services during household visits. Each household is visited at least once every calendar quarter. Services are provided in the areas of health and HIV, food and nutrition, psychosocial care and support, economic strengthening, education, and child protection. A list of categories of the services provided by the USAID Kizazi Kipya project is published [43]. While some of these services are provided 
Table 1 Direct and/or referral services provided by the USAID Kizazi Kipya project to OVC caregivers in Tanzania

\begin{tabular}{|c|c|}
\hline Service domain & List of Services \\
\hline \multirow[t]{23}{*}{ Health } & HIV testing and counseling \\
\hline & HIV care and treatment \\
\hline & ART adherence education \\
\hline & HIV prevention education \\
\hline & HIV disclosure support \\
\hline & TB/HIV screening \\
\hline & PMTCT services \\
\hline & STI treatment services \\
\hline & Opportunistic infections treatment (Ols) \\
\hline & Home Based Care Services (HBC) \\
\hline & Post Exposure Prophylaxis (PEP) \\
\hline & Antenatal care services (ANC) \\
\hline & Labor and delivery \\
\hline & Postnatal services \\
\hline & Family Planning (FP) \\
\hline & Immunization \\
\hline & Integrated management of childhood illness (IMCI) \\
\hline & Early Childhood development /Care for Child Development \\
\hline & Deworming \\
\hline & Malaria prevention \\
\hline & Diarrhea treatment \\
\hline & Mental Health services \\
\hline & Non-Communicable Diseases (NCDs) \\
\hline \multirow[t]{4}{*}{ Food and nutrition } & Nutrition status assessment, counselling and support \\
\hline & General food support \\
\hline & Supplemental feeding services \\
\hline & Therapeutic feeding services \\
\hline \multirow[t]{5}{*}{ Psychosocial care and support } & Counselling \\
\hline & Social participation \\
\hline & Child welfare education \\
\hline & Cultural and Spiritual support services \\
\hline & Alcohol and Drug Abuse Support \\
\hline \multirow[t]{4}{*}{ Economic strengthening } & Cash Transfers (TASAF)/Savings and Lending Support \\
\hline & $\begin{array}{l}\text { Income generating activity (IGA), small business/enterprise } \\
\text { support }\end{array}$ \\
\hline & Vocation skills support \\
\hline & Agricultural and extension service support \\
\hline
\end{tabular}

directly, referrals are issued and tracked for the services that the project does not directly provide, such as HIV testing, HIV treatment, and many others. At enrollment, HIV status was enquired of each caregiver, observing their right to autonomy as well as respecting their privacy. This information informed the development of a care plan which responded to the holistic needs of each household member, including HIV needs of the caregiver.

\section{Study design and data collection tools}

This study used a longitudinal design [44], whereby enrollment data (2017-2018) established the baseline, and, following one to $2 \frac{1}{2}$ years of service delivery, midline 
data was collected from the same beneficiaries in 2019 . The FCAA tool which was used at both surveys, captured caregivers' demographic information, household assets, sources of income, HIV status, food security, and use of and adherence to antiretroviral therapy (ART) for those who reported their HIV status as positive.

\section{Study area}

Data for this study originate from 81 district councils in 25 regions of Tanzania (44\% of district councils and 81\% of regions in the country) where the USAID Kizazi Kipya project had implemented screening and enrollment activities in 2017-2018.

\section{Study population}

The current study is based on a cohort of 140,664 OVC caregivers who were enrolled in the USAID Kizazi Kipya project during 2017-2018 and reported that they have tested for HIV and know their HIV status. Caregivers who had not tested for HIV at enrollment, or exited the project for any reason (e.g. lost to follow-up (LTFU), died or moved away) before 2019, or not interviewed for the midline survey were not included in this study. The study followed the caregivers through project service delivery between 2017 and 2019, and their midline assessment in 2019. Therefore, each caregiver included in the current study had two measurements of HIV status disclosure: one at the baseline and the other at the midline. A caregiver is defined by the USAID Kizazi Kipya project as a guardian who has the greatest responsibility for the daily care and rearing of one or more OVC in a household. A caregiver is not necessarily a biological parent of the OVC.

\section{Variables}

Caregivers' voluntary disclosure of their own HIV status to the USAID Kizazi Kipya project's volunteers (i.e. LCWs or CCWs) was the outcome variable for the current study. Caregivers who reported that they have been tested for HIV, were subsequently asked to voluntarily report their test results in order for the volunteer to establish and provide needed services. Caregivers who reported their HIV results as negative or positive were grouped together and referred to as 'disclosed', and those who knew their status but did not report it to the volunteer were documented as 'undisclosed'.

Pre and post intervention timings of HIV status disclosure was used in this study as the explanatory variable of interest. This fell into two categories: (1) baseline disclosure, i.e. HIV status disclosed at enrollment prior to USAID Kizazi Kipya service delivery, and (2) midline disclosure, i.e. HIV status disclosed to the USAID Kizazi Kipya project staff after the caregiver had received
USAID Kizazi Kipya services for up to $2 \frac{1}{2}$ years depending on their enrollment date.

Other explanatory variables included in this study were caregiver sex, age, education, marital status, household level of hunger, type of residence (rural or urban), and physical or mental disability. Rural residence included all those living in district councils, whereas those living in townships, municipal or city councils were classified as urban residents. Household level of hunger was measured using the Household Hunger Scale (HHS) [45] and had three categories: (1) little to no hunger (food secure), (2) moderate hunger, and (3) severe hunger.

\section{Data analysis}

All statistical analyses were performed using Stata 14.0 statistical software. Distributional features of the caregivers were obtained through one-way tabulations. For both baseline and midline surveys, the association between HIV status disclosure and each of the independent variables was tested using the Chi-Square $\left(x^{2}\right)$ test because all variables were categorical. Comparison between baseline and midline disclosure rates was made using McNemar's test because baseline disclosure observations of the same caregivers were paired to their midline counterparts [4648]. Disclosure rates in each of the individual categories of the independent variables at midline and baseline were compared using immediate form of two-sample test of proportions [49].

Multivariable analysis of factors associated with HIV status disclosure among the caregivers was conducted using generalized estimating equation (GEE) with logit link function, binomial distribution family and an exchangeable correlation structure. Since HIV status disclosure was measured twice (i.e., at baseline and at midline) for each caregiver, their disclosure observations were assumed to be correlated. Therefore, this made the GEE the most appropriate model because it addresses within-subject correlations and both time-dependent and time-independent covariates [50-55]. The model took the following form:

$$
\mathrm{Y}_{\mathrm{it}}=\beta_{0}+\sum_{\mathrm{j}=1}^{\mathrm{J}} \beta_{1 \mathrm{j}} \mathrm{X}_{\mathrm{itj}}+\beta_{2} \mathrm{t}+\cdots+\mathrm{CORR}_{\mathrm{it}}+\varepsilon_{\mathrm{it}}
$$

where $Y_{i t}$ are HIV status disclosure observations for caregiver $i$ at time $t, \beta_{0}$ is the intercept, $X_{i j t}$ is the independent variable $j$ for caregiver $i$ at time $t, \beta_{1 j}$ is the regression coefficient for independent variable $j$, $J$ is the number of independent variables, $t$ is time $\left(t_{0}=\right.$ baseline, and $t_{1}=$ midline), $\beta_{2}$ is the regression coefficient for time, $\mathrm{CORR}_{\text {it }}$ is the working correlation structure (exchangeable in this case), and $\varepsilon_{\mathrm{it}}$ is the 'error' term for caregiver $i$ at time t. HIV status disclosure was measured at two 
time points: at baseline $\left(t_{0}\right)$ where caregivers were being enrolled into the project and had not received any services from the USAID Kizazi Kipya project; and at the midline $\left(\mathrm{t}_{1}\right)$ where all caregivers had received program services. In the model specification, coefficients were exponentiated using Stata's 'eform' option to obtain adjusted odds ratios (ORs) and their corresponding 95\% confidence intervals (CIs). Statistical inferences were made at a significance level of $5 \%$, whereby factors corresponding with $p$-values $\leq 0.05$ were considered statistically significant in the prediction of HIV status disclosure.

\section{Results}

Baseline profile of respondents

As shown in Table 2, the current study is based on 140,664 caregivers of OVC, $72.2 \%$ of whom were female.

Table 2 Baseline socio-demographic profile of respondents

\begin{tabular}{|c|c|c|}
\hline Variable & $\begin{array}{l}\text { Number of Caregivers } \\
\text { (n) }\end{array}$ & Percent (\%) \\
\hline $\mathrm{ALL}$ & 140,664 & 100.0 \\
\hline \multicolumn{3}{|l|}{ Sex } \\
\hline Female & 101,557 & 72.2 \\
\hline Male & 39,107 & 27.8 \\
\hline \multicolumn{3}{|l|}{ Age (years) } \\
\hline $18-29$ & 11,292 & 8.0 \\
\hline $30-39$ & 34,184 & 24.3 \\
\hline $40-49$ & 40,522 & 28.8 \\
\hline $50-59$ & 24,405 & 17.4 \\
\hline $60+$ & 30,261 & 21.5 \\
\hline Mean $=47.4, S D=14.2$ & - & - \\
\hline \multicolumn{3}{|l|}{ Marital status } \\
\hline Married or living together & 69,421 & 49.4 \\
\hline Divorced or separated & 17,386 & 12.4 \\
\hline Never been married & 9941 & 7.1 \\
\hline Widow/widower & 43,916 & 31.2 \\
\hline \multicolumn{3}{|l|}{ Education } \\
\hline Never attended & 28,704 & 20.4 \\
\hline Primary & 107,092 & 76.1 \\
\hline Secondary + & 4868 & 3.5 \\
\hline \multicolumn{3}{|l|}{ Place of residence } \\
\hline Rural & 76,548 & 54.4 \\
\hline Urban & 64,116 & 45.6 \\
\hline \multicolumn{3}{|l|}{ Household Hunger Scale } \\
\hline Little to no hunger & 37,257 & 26.5 \\
\hline Moderate hunger & 91,147 & 64.8 \\
\hline Severe hunger & 12,260 & 8.7 \\
\hline \multicolumn{3}{|c|}{ Caregiver mentally or physically disabled? } \\
\hline No & 135,799 & 96.5 \\
\hline Yes & 4865 & 3.5 \\
\hline
\end{tabular}

At enrollment (the baseline), they were aged at least 18 years and their mean age was 47.4 years (standard deviation $[\mathrm{SD}]=14.2)$. About half $(49.4 \%)$ of the caregivers were married or living together with their spouses; and $76.1 \%$ had some primary education.

Slightly more than a half (54.4\%) resided in rural areas; and $3.5 \%$ were mentally or physically disabled. With respect to food security, the majority $(64.8 \%)$ were in households with moderate hunger, and $8.7 \%$ in severe hunger households (Table 2).

Between baseline and midline, the caregivers had received services from the USAID Kizazi Kipya project for different durations depending on their enrollment dates. Earlier enrollees received services for a longer duration than those who enrolled later. From baseline (enrollment) to midline, the mean duration of exposure to the project was 1.4 years, ranging from 0.4 to 2.5 years $(\mathrm{SD}=0.5)$ (Fig. 1).

\section{HIV status disclosure rates $b$ etween baseline and midline}

As presented in Fig. 2, overall, caregivers' HIV status disclosure to the USAID Kizazi Kipya project staff was $81.3 \%$ at baseline and $96.1 \%$ by midline, (an increase of $14.8 \%, \mathrm{p}<0.001$ ). Similarly, McNemar's comparison of the disclosure rates at the two time points indicated that, the likelihood of disclosure was six times higher at midline than at baseline (odds ratio $[\mathrm{OR}]=6.1,95 \%$ confidence interval [CI] 5.9-6.3). Caregivers who disclosed their HIV status were subsequently linked to appropriate services per their status, and those who did not were encouraged to do so as soon as they are comfortable. Referral services provided by the project are published elsewhere [43]. Ultimately, all the caregivers, regardless of their HIV status, were linked to other program services depending on established needs.

\section{HIV status disclosure rates between baseline and midline, by baseline characteristics}

As seen in Fig. 2, caregivers' disclosure of their HIV status to the USAID Kizazi Kipya project staff at baseline varied significantly by their baseline characteristics: female caregivers were more likely to disclose than their male counterparts $(\mathrm{p}<0.001)$. After age 39 , disclosure declined consistently to the lowest level of $70.8 \%$ among the oldest caregivers aged 60 years and above $(\mathrm{p}<0.001)$. Disclosure was highest among caregivers who were single or never married and lowest among those who were widowed $(\mathrm{p}<0.001)$. With respect to education, the rate of disclosure increased consistently with education, and pinnacled to $86.2 \%$ among caregivers with secondary education or more $(\mathrm{p}<0.001)$. Disclosure was better in urban than in rural areas $(\mathrm{p}<0.001)$. The disclosure rate 


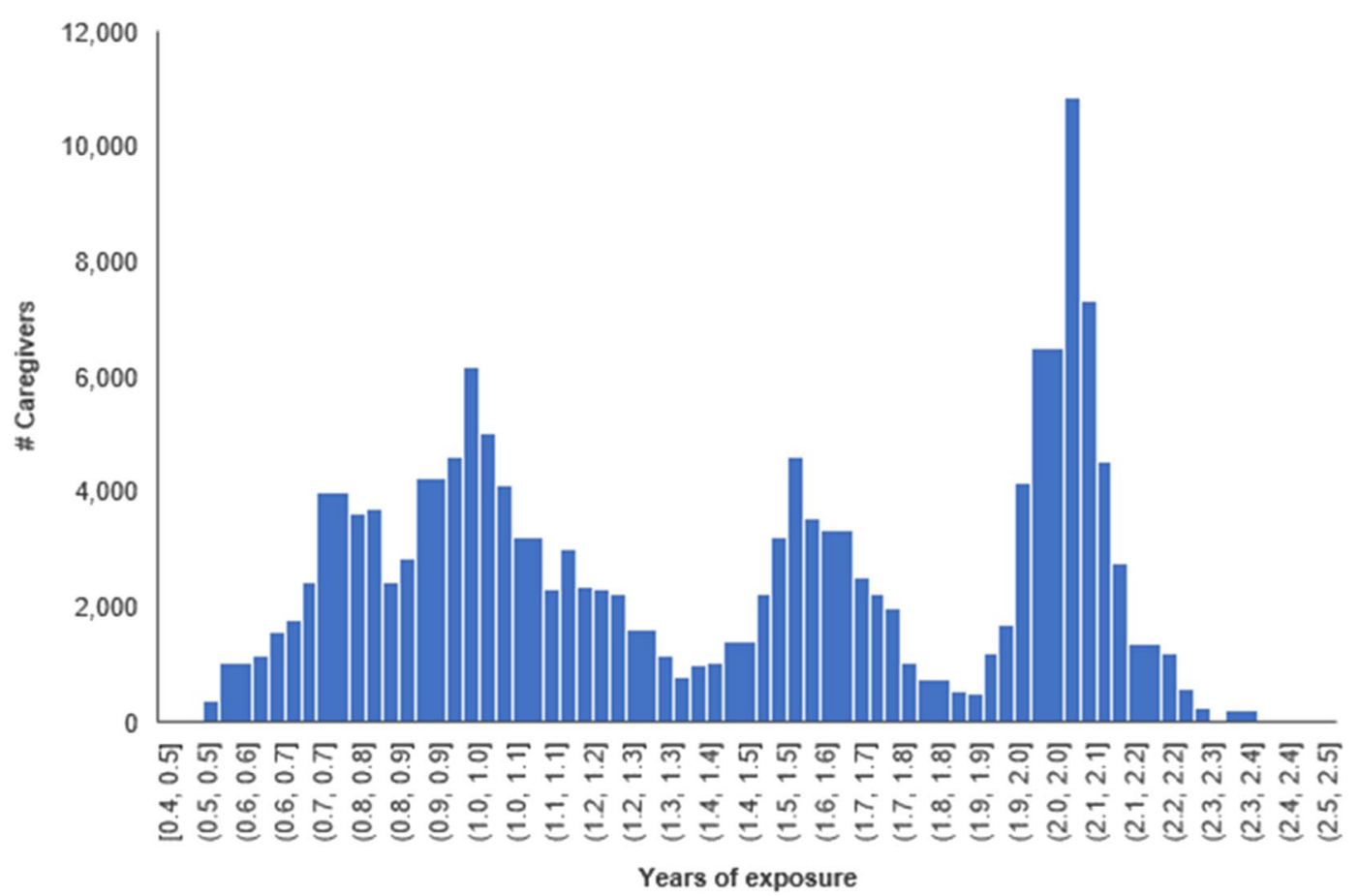

Fig. 1 Caregivers' duration of exposure to the USAID Kizazi Kipya project from baseline (enrollment) to midline $(n=140,664)$

was lower among caregivers who were mentally or physically disabled than those who were not $(\mathrm{p}<0.001)$. Finally, the rate of HIV status disclosure among the caregivers increased steadily as the level of household hunger rose $(\mathrm{p}<0.001)$.

At the midline, apart from place of residence-whereby rural caregivers were more likely to disclose than their urban counterparts $(\mathrm{p}<0.001)$ - the variations in rates of HIV status disclosure by the caregivers' baseline characteristics were no longer present $(p>0.050)$, and the rate was around $96.0 \%$ across the characteristics.

\section{Midline disclosure rates by duration of exposure to the USAID Kizazi Kipya project}

There were 26,329 caregivers who did not disclose their HIV status to the program staff at baseline. Of these, 94.7\% $(\mathrm{n}=24,933)$ disclosed at midline, and $10.2 \%$ $(n=2,675)$ of them were HIV positive and subsequently linked to appropriate HIV services. Those who were HIV negative received HIV prevention knowledge and where they can access more information about HIV and AIDS. Again, all caregivers, regardless of their HIV status, were linked to other program services depending on established needs.

As shown in Fig. 3, overall, HIV status disclosure in this group had an increasing trend with an increasing duration of exposure to the program, from $90.9 \%$ among caregivers who had been in the program for 9 months or less to $94.1 \%$ among caregivers who had been in the program for more than $2 \frac{1}{4}$ years. The highest disclosure rate was $96.4 \%$ among caregivers who had been in the program between $1 \frac{3 / 4}{4}$ and 2 years.

In Fig. 4, all the 140,664 caregivers' midline HIV status disclosure rates by the duration of exposure to the USAID Kizazi Kipya project were stratified by whether there was a change of the volunteer. Results showed that, the disclosure trend was slightly increasing as the duration of exposure to the project increased if the volunteer remained the same but decreasing if the volunteer was different.

Further stratifications of the midline disclosure rates were made by considering baseline HIV status (positive, negative, and undisclosed) and whether the volunteer remained the same from baseline to midline (Fig. 5). Results revealed that the disclosure trend was rapidly increasing over time for caregivers who had not disclosed their HIV status at baseline and had the same volunteer ( $\mathrm{n}=17,687$ ) (from $89.7 \%$ for caregivers who had been in the project for 9 months or less to $98.7 \%$ for those who had been in the project for more than $2 \frac{1}{4}$ years). The rest of the disclosure trends for different groups of the caregivers were not significantly changing over time, except those who were HIV negative at baseline and had a different volunteer $(n=15,912)$ whose disclosure trend 


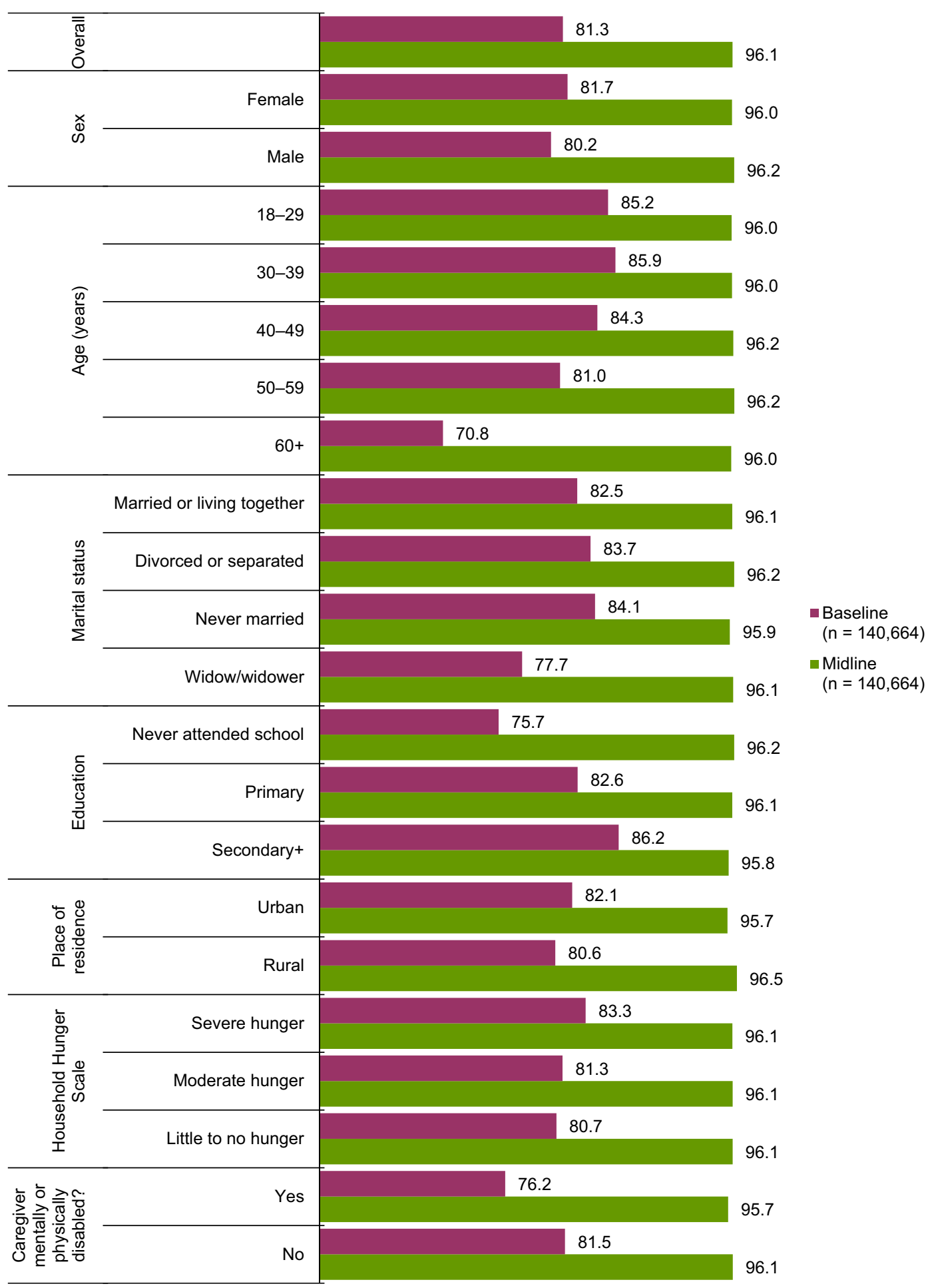

Fig. 2 Rates (\%) of HIV status disclosure at baseline and at midline by baseline characteristics among 140,664 caregivers of OVC in Tanzania

was significantly declining (from 95.8 to $93.3 \%$ among those who had been in the project for 9 months or less and more than $2 \frac{1}{4}$ years, respectively).
Increase in disclosure rates from baseline to midline by baseline characteristics

Figure 6 is derived from Fig. 2 and shows the amount of 


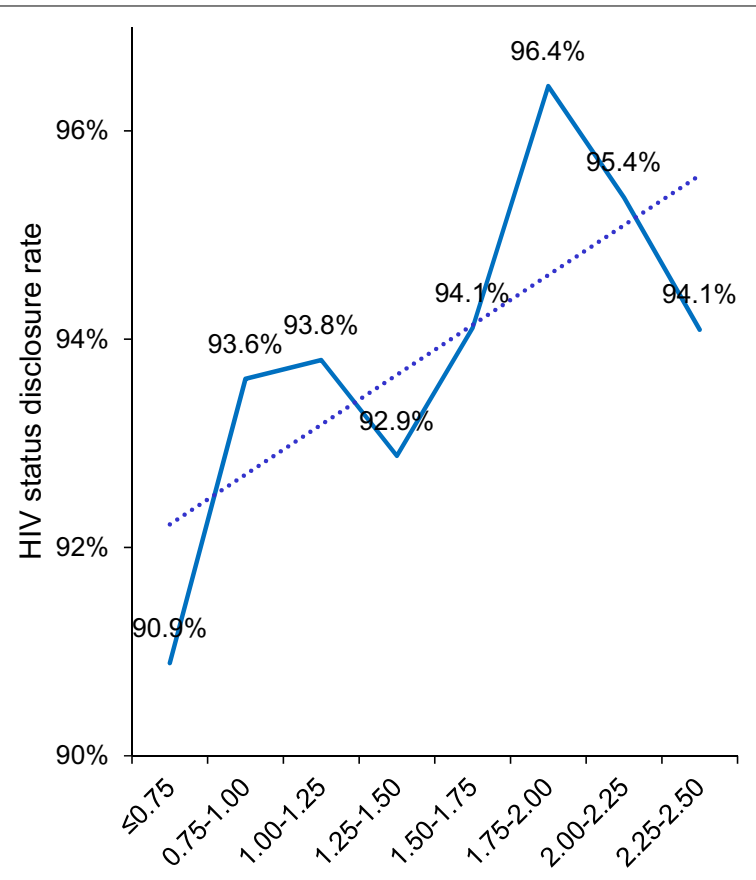

Years of exposure to the USAID Kizazi Kipya project

Fig. 3 Midline HIV status disclosure rates among 26,329 caregivers who had not disclosed their HIV status at baseline by duration of exposure to the USAID Kizazi Kipya project

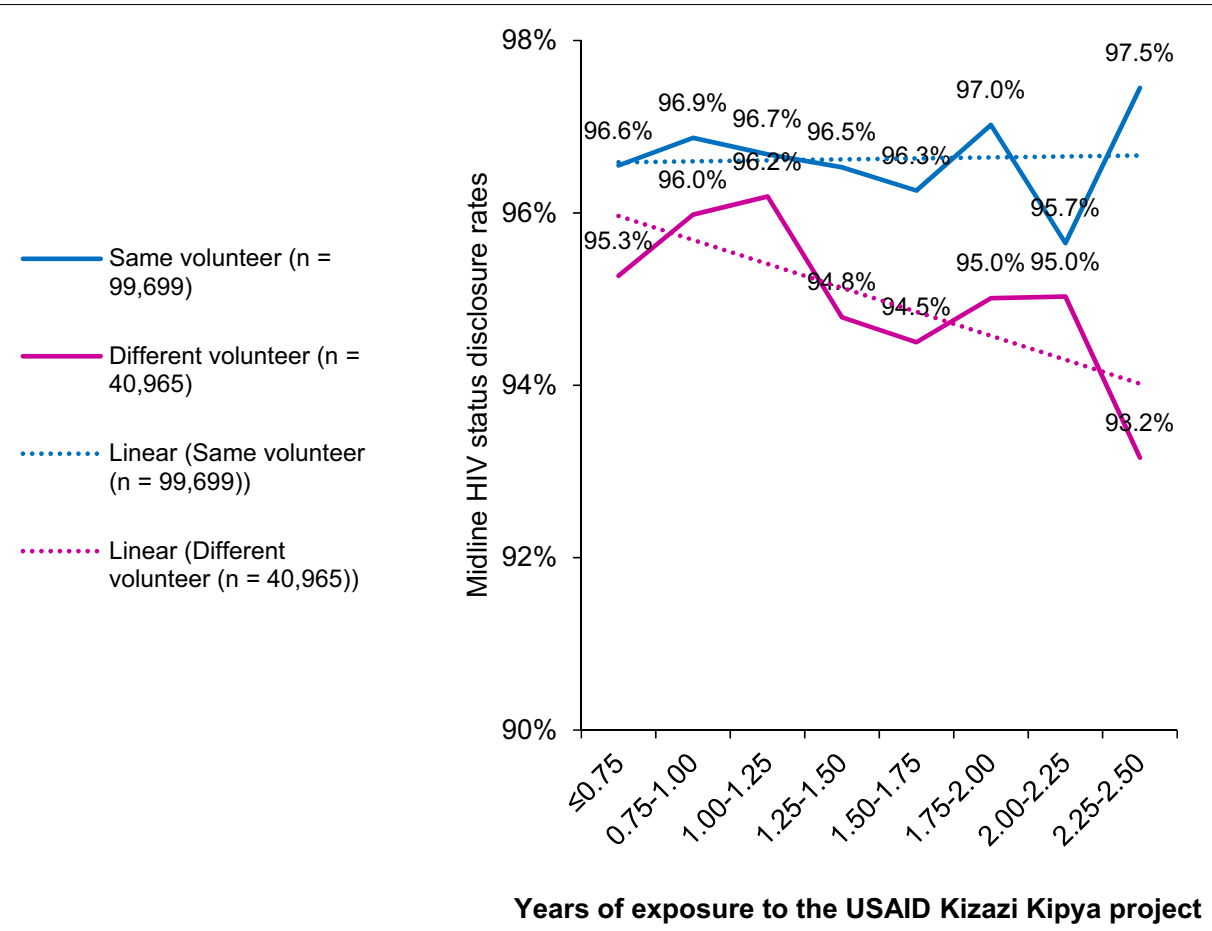

Fig. 4 Midline HIV status disclosure rates (stratified by whether the volunteer changed) by duration of exposure to the USAID Kizazi Kipya project 


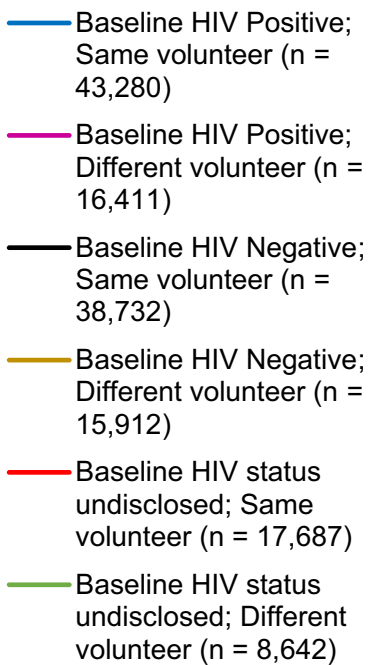

Baseline HIV Positive Same volunteer $(\mathrm{n}=$ Different volunteer $(\mathrm{n}=$ Same volunteer $(\mathrm{n}=$ 38,732) Different volunteer $(\mathrm{n}=$ 15,912) undisclosed; Same volunteer $(n=17,687)$ volunteer $(n=8,642)$

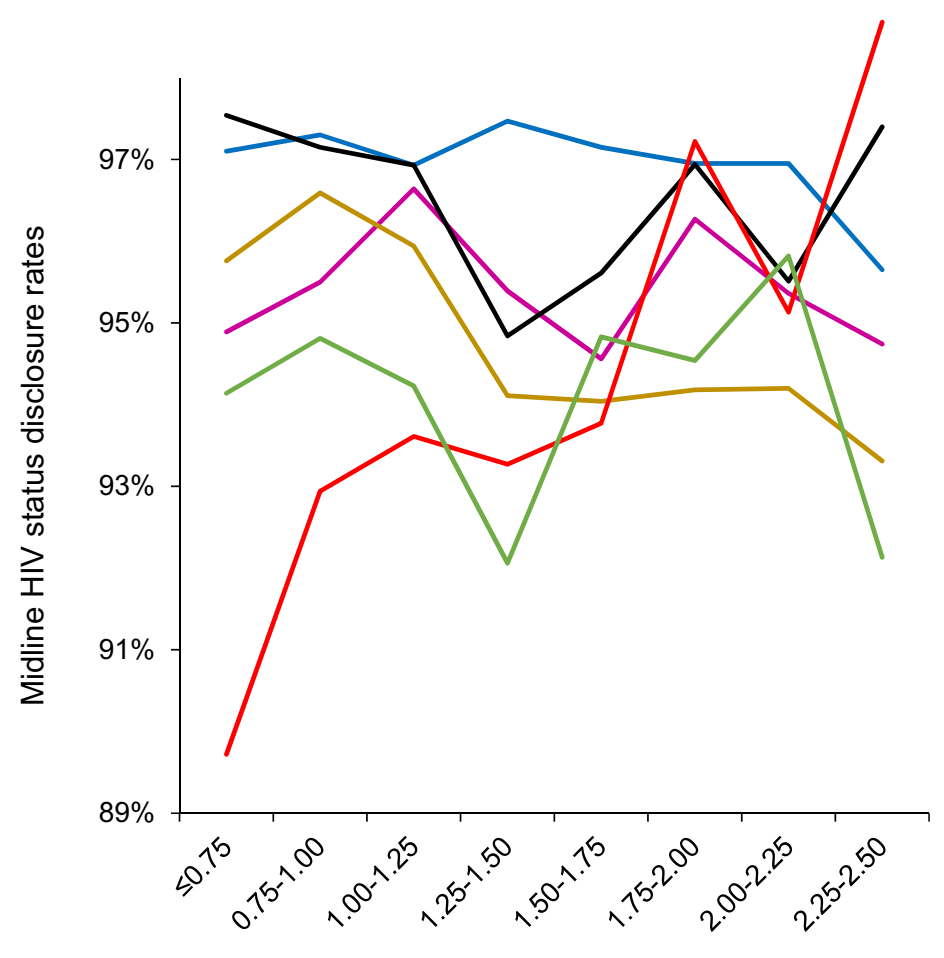

Years of exposure to the USAID Kizazi Kipya project

Fig. 5 Caregivers' midline HIV status disclosure rates stratified by baseline HIV status and whether the volunteer changed by duration of exposure to the USAID Kizazi Kipya project

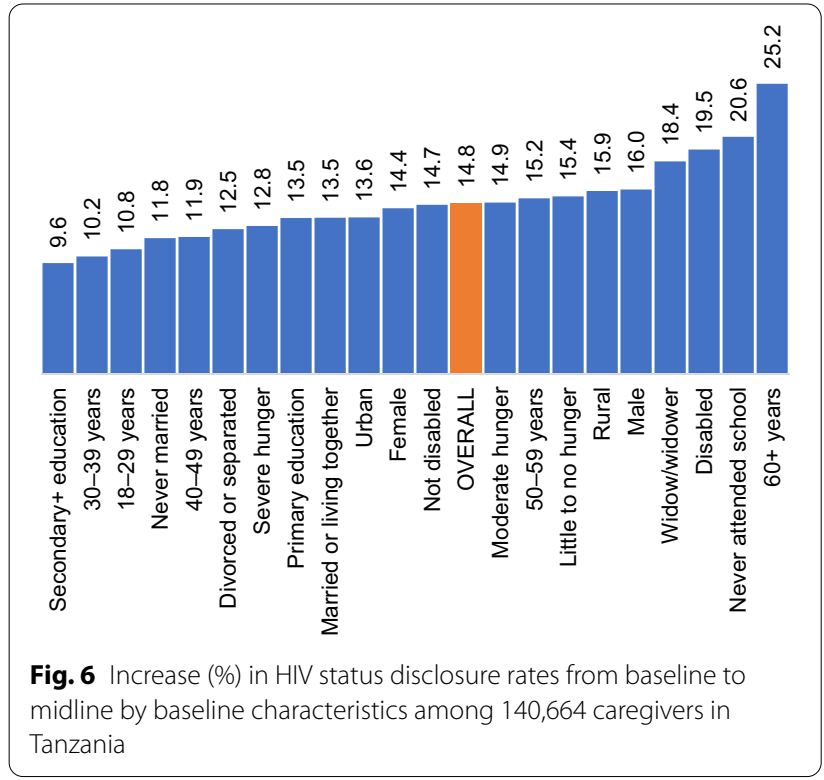

change in disclosure rates between baseline and midline across different caregivers' baseline characteristics. The project effect on disclosure (as measured at midline) was largest where disclosure was lowest at baseline, ranging from 9.6\% among those who had secondary + education to $25.2 \%$ among those who were aged 60 years or more, with an average disclosure gain of $14.8 \%$ (Fig. 6).

\section{Results of multivariable analysis}

Figure 7 shows multivariable GEE model of factors associated with HIV status disclosure among the caregivers. Adjusted odds ratios (ORs) and their corresponding 95\% confidence intervals (CIs) are presented. Factors are adjusted for one another in the model, and the subsequent interpretations embeds this fact.

The analysis uncovered that caregivers' likelihood of HIV status disclosure was nearly 6 times higher at midline than at baseline, when the baseline characteristics were adjusted for $(\mathrm{OR}=5.76,95 \%$ CI $5.59-5.94$, $p<0.001$ ).

In addition, with all factors adjusted for one another, male caregivers were $5 \%$ less likely to disclose their HIV status than their female counterparts $(\mathrm{OR}=0.95$, 95\% CI 0.92-0.98, $\mathrm{p}<0.001)$. Caregivers in the age group 30-39 years were $7 \%$ more likely to disclose their HIV status than the youngest age 18-29 years $(\mathrm{OR}=1.07,95 \%$ CI 1.01-1.13, $\mathrm{p}=0.017)$. Subsequent age groups were each less likely to disclose their HIV status than the youngest age group, with significance 


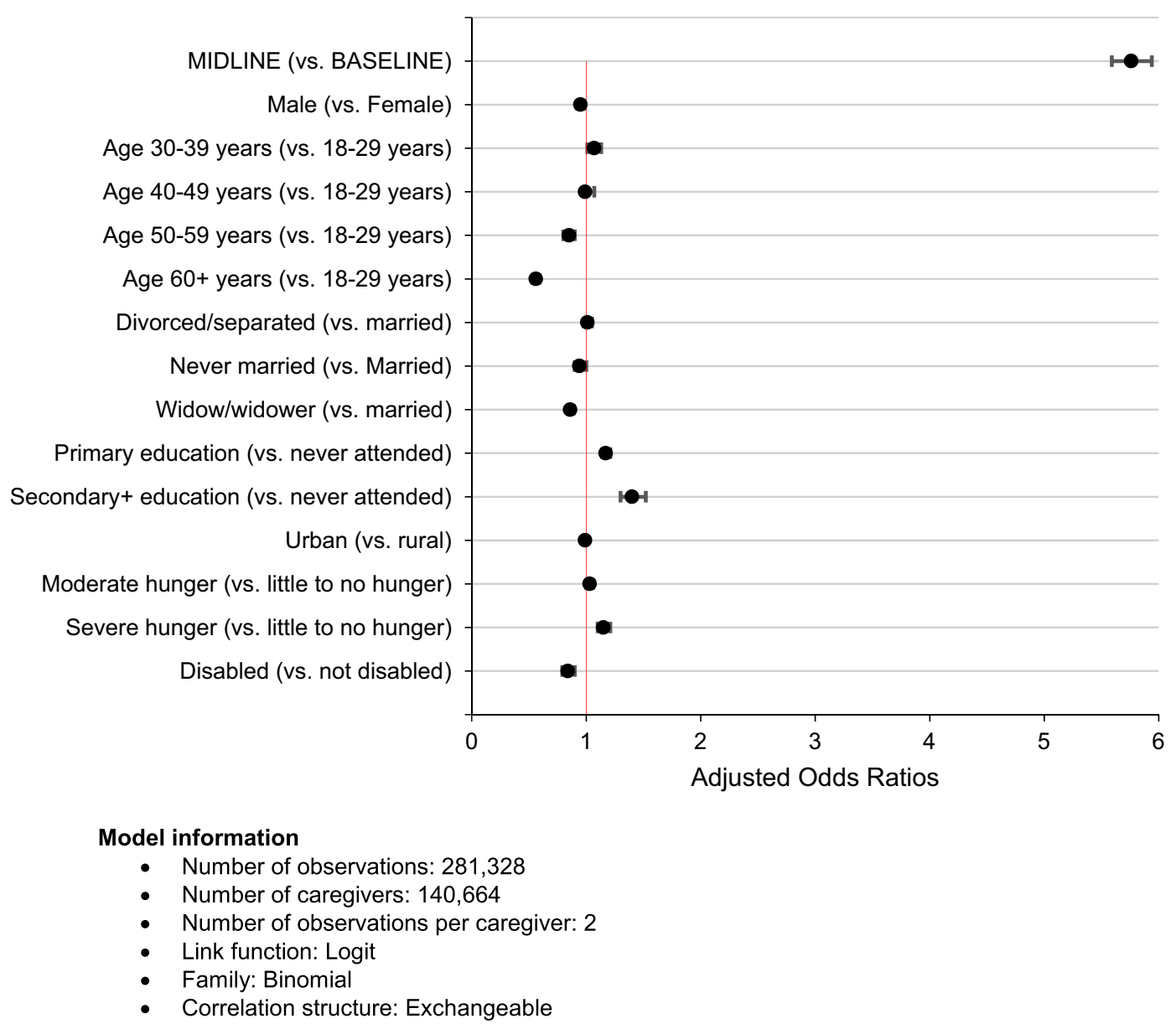

Fig. 7 Multivariable generalized estimating equation (GEE) of factors associated with HIV status disclosure among OVC caregivers in Tanzania

only for age groups $50-59$ years $(\mathrm{OR}=0.85,95 \% \mathrm{CI}$ $0.80-0.90, \mathrm{p}<0.001)$, and $60+$ years $(\mathrm{OR}=0.56,95 \%$ CI $0.53-0.59, \mathrm{p}<0.001)$. Widowed caregivers were $14 \%$ less likely compared to those who were married or living together with their spouses to disclose their HIV status $(\mathrm{OR}=0.86,95 \%$ CI $0.84-0.89, \mathrm{p}<0.001)$. With respect to education, both primary $(\mathrm{OR}=1.17,95 \% \mathrm{CI}$ $1.14-1.21, \mathrm{p}<0.001)$ and secondary or more education $(\mathrm{OR}=1.40,95 \%$ CI 1.30-1.52, $\mathrm{p}<0.001)$ levels were more likely to improve HIV status disclosure than no education.

Furthermore, the likelihood of HIV status disclosure increased with increasing levels of household hunger, from $3 \%$ among caregivers in moderate hunger $(\mathrm{OR}=1.03,95 \% \mathrm{CI} 1.00-1.06, \mathrm{p}=0.049)$ to $15 \%$ among those in severe hunger households $(\mathrm{OR}=1.15,95 \%$ CI $1.10-1.21, \mathrm{p}<0.001)$. Finally, caregivers who were physically or mentally disabled were $16 \%$ less likely to disclose their HIV status than those without the disabilities (OR $=0.84,95 \%$ CI 0.79-0.90, $\mathrm{p}<0.001)$.

\section{Discussion}

This study assessed the contribution of the USAID Kizazi Kipya project's model of community-based service delivery through social welfare volunteers on HIV status disclosure rates among 140,664 caregivers of OVC in Tanzania at baseline and at midline. Results showed an increase of $14.8 \%$ in caregivers' HIV status disclosure to the program staff from $81.3 \%$ at baseline to $96.1 \%$ at midline in an average exposure period of 1.4 years. In the multivariable analysis, HIV status disclosure was about six times more likely at midline than at baseline, when baseline characteristics of the caregivers were adjusted for. Note that at the midline, all the caregivers had received some services from the USAID Kizazi Kipya project, including disclosure support for those who had not disclosed their HIV status at the baseline. This means 
that the project successfully improved caregivers' HIV status disclosure, and consequently expanded service coverage.

Out of the caregivers who did not disclose their HIV status at baseline (i.e., 0\% disclosure rate at baseline), 94.7\% disclosed at midline, and their disclosure trend was increasing as their duration of exposure to the program increased. This increase was very rapid if the volunteer remained the same. The USAID Kizazi Kipya project intervention contributed to this achievement, especially through the disclosure support services provided to the caregivers who had not disclosed their HIV status at baseline. This means that the project was successful in encouraging HIV status disclosure among the caregivers, and consequently expanded coverage of its HIV services, thus contributing to the United Nations' sustainable development goal 3 of universal health coverage [56]. The community volunteers' facilitated HIV status disclosure rate observed in this study was much higher than the health provider facilitated rate of $39 \%$ estimated in a similar study among postpartum women who had not yet disclosed their status in three health facilities in Tanzania [16].

On the other hand, if the volunteer changed over the course of service delivery, the disclosure trends became horizontal or declining over time in different groups of the caregivers, particularly those who disclosed their HIV status at baseline as HIV negative. Although the change of the volunteer was due to causes beyond the project control (e.g. drop out, death etc.), the finding cemented the importance of trust [57] in HIV status disclosure which takes time to build. Therefore, introducing a new volunteer to the caregivers implied that the volunteer-caregiver relationship building had to start afresh, hence resulting in declining disclosure rates: some of the caregivers who disclosed at baseline didn't disclose at midline, mainly because the volunteer changed. This highlights the need for community-based volunteer-driven programs to devise mechanisms to minimize dropout of volunteers because it is pernicious, and this may not be limited to HIV status disclosure. Further research is needed to explore factors affecting volunteers' satisfaction and retention, and suggest possible ways to address their drop out in community-based programs. Also, research should explore the extent to which trust, safety and comfortability are ensured during the process of handing over caregivers and other beneficiaries of community-based programs to new volunteers.

In addition, this study uncovered several other factors with significant association with HIV status disclosure. With respect to sex, multivariable analysis showed that male caregivers were less likely to disclose than their female counterparts. This was also observed in one review study [9]. Previous studies have reported poor health seeking behaviour among men than women [58, 59], which is why they may also be less likely to disclose their HIV status. The current study demonstrates that the intervention was effective in bridging the disclosure gap between men and women, thus a need to continue disclosure support interventions, with additional support for men. As similarly observed in other studies [13, 23-25], HIV status disclosure in the current study was less likely among widowed than married caregivers. It is expected that caregivers in marital unions are more likely to disclose to their spouses because they are in contact with each other for improved communication and trust in each other than those who are widowed [13]. Therefore, since widowed caregivers may have difficulties in disclosing their HIV status, possibly due to lack of social support [60] and or stigma and discrimination, targeted disclosure support interventions are important. In the current study, the observed differences in disclosure rates by marital status at baseline disappeared at midline, hence revealing effectiveness of the USAID Kizazi Kipya project in addressing gender-related barriers to HIV status disclosure. Further research should explore specific gender-related factors that influence HIV status disclosure.

Disclosure by age pinnacled among those who were aged 30-39 years, after which the likelihood to disclose started to decline in the subsequent age groups $40-49$, $50-59$, and $60+$ years than the youngest caregivers in the age group 18-29 years. These observations are similar to others in Kenya [23] and Nigeria in [24]. Further research is required to explore why this was the case.

The likelihood of HIV status disclosure increased with increasing education. This is consistent with other studies $[22,32]$. This suggests that as better education improves self-esteem and confidence [61], communication skills improves as well [32] and consequently contributing to improved HIV status disclosure. Therefore, while formal education attainment should continue to be emphasized and expanded for universal coverage for longer term gain, interventions to enhance disclosure such as the USAID Kizazi Kipya are necessary especially for those who are unable to go back to school.

Surprisingly, the likelihood of HIV status disclosure increased with increasing levels of household hunger. Unfortunately, we did not clearly understand how this relationship came into existence. We thus recommend further research to explore and explain the underlying pathways for this observation. In the descriptive analysis, the differences in disclosure rates by household level of hunger were significant at baseline but vanished at the midline following the USAID Kizazi Kipya intervention. This suggests that the project successfully addressed 
hunger-related barriers to HIV status disclosure, and the current efforts should be sustained to ultimately achieve total disclosure.

Finally, disclosure was less likely among caregivers who were mentally or physically disabled than those without the disabilities. Some studies have shown that disability connotes stigma [62,63], a situation which has been shown that it increases fears of disclosure (9). Therefore, disabled people should be targeted with additional disclosure support. With the disclosure support provided by the USAID Kizazi Kipya project, disclosure rates at the midline were similar among caregivers with and without disability.

\section{Limitations}

While the USAID Kizazi Kipya project invests heavily towards enhancing HIV status disclosure and service uptake among beneficiaries, an optimum quantification of its effect may be difficult to realize because the inherent design of the project did not comprise a control group.

\section{Conclusions}

Lay social welfare volunteers provide continuous and frequent household support for a wide range of needs, such as economic strengthening, parenting, and violence prevention and response. Through the volunteers known as LCWs and CCWs, the USAID Kizazi Kipya project in Tanzania contributed to the increased caregivers' HIV status disclosure by $14.8 \%$, accelerating from $81.3 \%$ at baseline to $96.1 \%$ at midline within an average exposure period of 1.4 years. Of the caregivers who did not disclose their HIV status at baseline (i.e., $0 \%$ disclosure rate at baseline), $94.7 \%$ had disclosed by midline and their disclosure trends increased with increasing duration of exposure to the program, and the increase was very rapid if the volunteer remained the same from baseline to midline.

The observed differences in disclosure rates by baseline characteristics were clearly larger at baseline, but had disappeared by midline, suggesting that the USAID Kizazi Kipya project greatly contributed to this achievement through its regular services provided through the community-based volunteers (i.e., LCWs and CCWs). The increase in disclosure rates between baseline and midline across all the caregivers' baseline characteristics were higher among caregivers who were less likely to disclose at baseline and vice versa. This suggested that the intervention gain was equitable among the caregivers, whereby the more needy experienced more gain in terms of HIV status disclosure, and ultimately all became similar at midline. This implies that community-based interventions are better-positioned to successfully address and possibly eliminate sociodemographic and contextual barriers to HIV status disclosure and possibly uptake of services and consequently improve health outcomes.

\begin{abstract}
Abbreviations
AIDS: Acquired immunodeficiency syndrome; ART: Antiretroviral therapy; CCWs: Community Case Workers; CHF: Community health fund; Cl: Confidence interval; FCAA: Family and child asset assessment; HIV: Human immunodeficiency virus; HHS: Household hunger scale; IHI: Ifakara Health Institute; LCWs: Lead Case Workers; LHIV: Living with HIV; LTFU: Loss/lost to follow-up; MRCC: Medical Research Coordinating Committee; NIMR: National Institute for Medical Research; OR: Adjusted odds ratio; OVC: Orphans and vulnerable children; PLHIV: People living with HIV; SD: Standard deviation; UNAIDS: Joint United Nations Programme on HIV and AIDS; USAID: United States Agency for International Development.
\end{abstract}

\section{Acknowledgements}

We acknowledge the support of the project staff, the consortium partners, Civil Society Organizations (CSOs), LCWs, CCWs, District Social Welfare Officers (DSWO), and everyone directly or indirectly involved in the implementation of the USAID Kizazi Kipya project in Tanzania. Dr. Eveline Geubbels from the Ifakara Health Institute (IHI) is highly appreciated for her critical review of the manuscript. Ms. Shraddha Bajaria from IHI is also acknowledged for her statistical advice. A poster version of this manuscript was presented at the $23 \mathrm{rd}$ International AIDS Conference (AIDS 2020: Virtual), 6-10 July 2020.

\section{Authors' contributions}

AE conceptualized the problem, conducted statistical analyses, reviewed the literature, drafted the manuscript, and revised subsequent versions. JC conducted problem refinement, study design, statistical analysis, and critical review of the manuscript. $A B$ participated in the study design, and critical review of the manuscript for intellectual content. EK participated in the study design, critically reviewed the manuscript for intellectual content and proofread the manuscript. GMM conducted critical review of the manuscript for intellectual content. CK, TM, AA, and RM critically reviewed the manuscript for intellectual content. LK and EJ conducted problem refinement, design, and critical review of the manuscript for intellectual content. All authors read and approved the final manuscript.

\section{Funding}

The USAID Kizazi Kipya is a 5-year project (July 2016 to June 2021) implemented in Tanzania with funding from the U.S. President's Emergency Plan for AIDS Relief (PEPFAR) through the United States Agency for International Development (USAID). The contents of this paper; the study design, data collection, analysis, and interpretation; and the manuscript's writing remain the sole responsibility of the authors and do not necessarily reflect the views of USAID or the United States Government.

\section{Availability of data and materials}

The datasets analyzed during the current study are owned by Pact Tanzania and are not publicly available due to confidentiality restrictions. Therefore, access to the data can be provided by Pact Tanzania only.

\section{Declarations}

\section{Ethics approval and consent to participate}

Ethics approval for this study was received from the Medical Research Coordinating Committee (MRCC) of the National Institute for Medical Research (NIMR) in Tanzania with certificate number NIMR/HQ/R.8a/Nol.IX/3024. Recruitment of beneficiaries into the USAID Kizazi Kipya program was voluntary. All households which were identified as eligible for the program per the program enrollment criteria, and accepted to be enrolled in the program, signed an informed consent form after which the enrollment followed. Project beneficiaries' information is stored very securely and confidentially, and datasets analyzed for the current study were anonymous. 


\section{Consent for publication \\ Not applicable.}

\section{Competing interests}

The authors declare that they have no competing interests.

\section{Author details}

1 Pact, P.O. Box 6348, Dar es Salaam, Tanzania. ${ }^{2}$ Pact, Inc., 1828 L St NW Suite 300, Washington, DC 20036, USA. ${ }^{3}$ National Institute for Medical Research (NIMR), P.O Box 9653, Dar es Salaam, Tanzania.

Received: 26 September 2020 Accepted: 12 March 2021

Published online: 01 April 2021

\section{References}

1. The Lancet HIV. HIV status disclosure in a digital age. Lancet HIV. 2018;5(6):e265.

2. Tang W, Cao B, Liu C, Pan S, Zhang Y, Ong J, et al. HIV serostatus disclosure from partners before sex: results from an online survey of Chinese men who have sex with men. Lancet. 2017:390:S76.

3. WHO. HIV Status Disclosure to Sexual Partners: Rates, Barriers and Outcomes for Women. Geneva, Switzerland:WHO; 2004. https://apps.who. int/iris/bitstream/handle/10665/42717/9241590734_summary.pdf;jsess ionid $=13$ CCE59FA4F342FFC01C415CB44913AA? sequence $=2$. Accessed 7 May 2020

4. King R, Katuntu D, Lifshay J, Packel L, Batamwita R, Nakayiwa S, et al. Processes and outcomes of HIV serostatus disclosure to sexual partners among people living with HIV in Uganda. AIDS Behav. 2008;12(2):232-43.

5. Miller AN, Rubin DL. Factors leading to self-disclosure of a positive HIV diagnosis in Nairobi, Kenya: people living with HIV/AIDS in the SubSahara. Qual Health Res. 2007;17(5):586-98.

6. Shacham E, Small E, Onen N, Stamm K, Overton ET. Serostatus disclosure among adults with HIV in the era of HIV therapy. AIDS Patient Care STDS. 2012;26(1):29-35

7. Cissé M, Diop S, Abadie A, Henry E, Bernier A, Fugon L, et al. Factors associated with HIV voluntary disclosure to one's steady sexual partner in mali: results from a community-based study. J Biosoc Sci. 2016:48(1):51-65.

8. Conserve DF, King G, Dévieux JG, Jean-Gilles M, Malow R. Determinants of HIV serostatus disclosure to sexual partner among HIV-positive alcohol users in Haiti. AIDS Behav. 2014;18(6):1037-45.

9. Obermeyer CM, Baijal P, Pegurri E. Facilitating HIV disclosure across diverse settings: a review. Am J Public Health. 2011;101(6):1011-23.

10. Antelman G, Smith Fawzi MC, Mbwambo J, Msamanga Gl, Hunter DJ, Fawzi WW. Predictors of HIV-1 serostatus disclosure: a prospective study among HIV-infected pregnant women in Dar es Salaam. Tanzania AIDS. 2001;15(14):1865-74

11. Kilewo C, Massawe A, Lyamuya E, Semali I, Kalokola F, Urassa E, et al. HIV counseling and testing of pregnant women in sub-Saharan Africa: experiences from a study on prevention of mother-to-child HIV-1 transmission in Dar es Salaam Tanzania. J Acquir Immune Defic Syndr. 2001;28(5):458-62.

12. Kiula ES, Damian DJ, Msuya SE. Predictors of HIV serostatus disclosure to partners among HIV-positive pregnant women in Morogoro Tanzania. BMC Public Health. 2013:13:433.

13. Damian DJ, Ngahatilwa D, Fadhili H, Mkiza JG, Mahande MJ, Ngocho JS, et al. Factors associated with HIV status disclosure to partners and its outcomes among HIV-positive women attending Care and Treatment Clinics at Kilimanjaro region, Tanzania. PLoS ONE. 2019;14(3):e0211921.

14. Yonah G, Fredrick F, Leyna G. HIV serostatus disclosure among people living with HIV/AIDS in Mwanza Tanzania. AIDS Res Ther. 2014;11:5.

15. Hallberg D, Kimario TD, Mtuya C, Msuya M, Björling G. Factors affecting HIV disclosure among partners in Morongo, Tanzania. Int J Afr Nurs Sci. 2019;10:49-54.

16. Geubbels E, Williams A, Ramaiya A, Tancredi D, Young S, Chantry C. HIV status disclosure among postpartum women in rural Tanzania: predictors, experiences and uptake of a nurse-facilitated disclosure intervention. AIDS Care. 2018. https://doi.org/10.1080/09540121.2018.1428724. Accessed 3 Aug 2020.
17. Przybyla SM, Golin CE, Widman L, Grodensky CA, Earp JA, Suchindran C. Serostatus disclosure to sexual partners among people living with HIV: examining the roles of partner characteristics and stigma. AIDS Care. 2013;25(5):566-72.

18. Hosseinzadeh H, Hossain SZ, Bazargan-Hejazi S. Perceived stigma and social risk of HIV testing and disclosure among Iranian-Australians living in the Sydney metropolitan area. Sex Health. 2012;9(2):171-7.

19. Dageid W, Govender K, Gordon SF. Masculinity and HIV disclosure among heterosexual South African men: implications for HIV/AIDS intervention. Cult Health Sex. 2012;14(8):925-40.

20. Longinetti $\mathrm{E}$, Santacatterina M, El-Khatib Z. Gender perspective of risk factors associated with disclosure of HIV status, a cross-sectional study in Soweto South Africa. PLOS ONE. 2014;9:e95440.

21. Antelman G, Smith Fawzi MC, Kaaya S, Mbwambo J, Msamanga Gl, Hunter DJ, et al. Predictors of HIV-1 serostatus disclosure: a prospective study among HIV-infected pregnant women in Dar es Salaam Tanzania. AIDS. 2001;15(14):1865-74.

22. Taraphdar P, Dasgupta A, Saha B. Disclosure among people living with HIV/AIDS. Indian J Commun Med. 2007;32(4):280.

23. Trinh TT, Yatich N, Ngomoa R, McGrath CJ, Richardson BA, Sakr SR, et al. Partner disclosure and early CD4 Response among HIV-infected adults initiating antiretroviral treatment in Nairobi Kenya. PLOS ONE. 2016;11(10):e0163594.

24. Amoran OE. Predictors of disclosure of sero-status to sexual partners among people living with HIV/AIDS in Ogun State Nigeria. Niger J Clin Pract. 2012;15(4):385-90.

25. Agbor IE, Etokidem AJ, Ugwa EA. Factors Responsible for Disclosure of HIV Seropositivity among Residents of Cross River State, Nigeria. In: Indian journal of community medicine : official publication of Indian Association of Preventive \& Social Medicine. 2017.

26. Alema HB, Yalew WA, Beyene MB, Woldu MG. HIV positive status disclosure and associated factors among HIV Positive Adults in Axum Health Facilities, Tigray, Northern Ethiopia. Sci J Public Health. 2015;3(1):61.

27. Gultie T, Genet M, Sebsibie G. Disclosure of HIV-positive status to sexual partner and associated factors among ART users in Mekelle Hospital. HIV/ AIDS Res Palliat Care. 2015;7:209-14.

28. Hayes-Larson E, Hirsch-Moverman Y, Saito S, Frederix K, Pitt B, Maama $\mathrm{BL}$, et al. Prevalence, patterns, and correlates of HIV disclosure among TB-HIV patients initiating antiretroviral therapy in Lesotho. AIDS Care. 2017;29(8):978-84

29. Ramlagan S, Matseke G, Rodriguez VJ, Jones DL, Peltzer K, Ruiter $R A C$, et al. Determinants of disclosure and non-disclosure of HIVpositive status, by pregnant women in rural South Africa. SAHARA J. 2018;15(1):155-63.

30. Whembolua G-L, Conserve DF, Thomas K, Tshiswaka DI, Handler L. HIV serostatus disclosure in the Democratic Republic of the Congo: a systematic review. AIDS Care. 2019:31(4):489-93.

31. Atuyambe LM, Ssegujja E, Ssali S, Tumwine C, Nekesa N, Nannungi A, et al. HIV/AIDS status disclosure increases support, behavioural change and HIV prevention in the long term: a case for an Urban Clinic, Kampala, Uganda. BMC Health Serv Res. 2014;14(1):276.

32. Kadowa I, Nuwaha F. Factors influencing disclosure of HIV positive status in Mityana district of Uganda. Afr Health Sci. 2009;9(1):26-33.

33. Kiarie JN, Kreiss JK, Richardson BA, John-Stewart GC. Compliance with antiretroviral regimens to prevent perinatal HIV-1 transmission in Kenya. AIDS. 2003;17(1):65-71.

34. Maman S, Mbwambo JK, Hogan NM, Weiss E, Kilonzo GP, Sweat MD. High rates and positive outcomes of HIV-serostatus disclosure to sexual partners: reasons for cautious optimism from a voluntary counseling and testing clinic in Dar es Salaam. Tanzania AIDS Behav. 2003;7(4):373-82.

35. Medley A, Garcia-Moreno C, McGill S, Maman S. Rates, barriers and outcomes of HIV serostatus disclosure among women in developing countries: implications for prevention of mother-to-child transmission programmes. Bull World Health Organ. 2004;82:299-307.

36. Walcott MM, Hatcher AM, Kwena Z, Turan JM. Facilitating HIV status disclosure for pregnant women and partners in rural Kenya: a qualitative study. BMC Public Health. 2013;13:1115.

37. Sariah A, Rugemalila J, Somba M, Minja A, Makuchilo M, Tarimo E, et al. "Experiences with disclosure of HIV-positive status to the infected child": Perspectives of healthcare providers in Dar es Salaam, Tanzania. BMC Public Health. 2016;16(1):1083. 
38. Vaz LME, Maman S, Eng E, Barbarin OA, Tshikandu T, Behets F. Patterns of Disclosure of HIV-Status to Infected Children in a Sub-Saharan African Setting. J Dev Behav Pediatr. 2011;32(4):307-15.

39. Vreeman RC, Gramelspacher AM, Gisore PO, Scanlon ML, Nyandiko WM. Disclosure of HIV status to children in resource-limited settings: a systematic review. J Int AIDS Soc. 2013;16:1.

40. Pinzón-Iregui MC, Beck-Sagué CM, Malow RM. Disclosure of Their HIV status to infected children: a review of the literature. J Trop Pediatr. 2013;59(2):84-9.

41. Exavery A, Charles J, Kuhlik E, Barankena A, Koler A, Kikoyo L, et al. Understanding the association between caregiver sex and HIV infection among orphans and vulnerable children in Tanzania: learning from the USAID Kizazi Kipya project. BMC Health Serv Res. 2020;20(1):275.

42. Exavery A, Charles J, Kuhlik E, Barankena A, Mubyazi GM, Kikoyo L, et al. Relationship between food insufficiency and HIV infection among caregivers of orphans and vulnerable children in Tanzania. HIV/AIDS Res Palliat Care. 2020;12:271-82.

43. Bajaria S, Abdul R, Exavery A, Minja E, Charles J, Mtenga S, et al. Programmatic determinants of successful referral to health and social services for orphans and vulnerable children: A longitudinal study in Tanzania. PLoS ONE. 2020;15(9).

44. Pearce N. Classification of epidemiological study designs. Int J Epidemiol. 2012;41(2):393-7.

45. Ballard T, Coates J, Swindale A, Deitchler M. Household Hunger Scale: Indicator Definition and Measurement Guide. Washington, DC: Food and Nutrition Technical Assistance II Project, FHI 360; 2011 p. 23. https:// www.fantaproject.org/sites/default/files/resources/HHS-Indicator-GuideAug2011.pdf

46. Caronni A, Sciumè L. Is my patient actually getting better? Application of the McNemar test for demonstrating the change at a single subject level. Disabil Rehabil. 2017:39(13):1341-7.

47. Fagerland MW, Lydersen S, Laake P. The McNemar test for binary matched-pairs data: mid- $p$ and asymptotic are better than exact conditional. BMC Med Res Methodol. 2013;13:91.

48. Westfall PH, Troendle JF, Pennello G. Multiple McNemar Tests. Biometrics. 2010;66(4):1185-91.

49. Kim H-Y. Statistical notes for clinical researchers: sample size calculation. 2 Comparison of two independent proportions. Restor Dent Endod. 2016;41(2):154-6.

50. Diggle P, Liang K-Y, Zeger SL. Analysis of longitudinal data. New York: Oxford University Press; 1994. p. 280.
51. Liang K-Y, Zeger SL. Longitudinal data analysis using generalized linear models. Biometrika. 1986;73(1):13-22.

52. Twisk JWR. Applied Longitudinal Data Analysis for Epidemiology: A Practical Guide. Cambridge: Cambridge University Press; 2003.

53. Zeger SL, Liang K-Y, Albert PS. Models for longitudinal data: a generalized estimating equation approach. Biometrics. 1988;44(4):1049-60.

54. Zeger SL, Liang KY. An overview of methods for the analysis of longitudinal data. Stat Med. 1992;11(14-15):1825-39.

55. Zeger SL, Liang K-Y. Longitudinal data analysis for discrete and continuous outcomes. Biometrics. 1986;42(1):121-30.

56. United Nations. \#Envision2030 Goal 3: Good Health and Well-being 2015. https://www.un.org/development/desa/disabilities/envision2030goal3.html. Accessed 15 May 2020.

57. Ssali SN, Atuyambe L, Tumwine C, Segujja E, Nekesa N, Nannungi A, et al. Reasons for Disclosure of HIV Status by People Living with HIV/AIDS and in HIV Care in Uganda: An Exploratory Study. AIDS Patient Care STDS. 2010;24(10):675-81.

58. Abaerei AA, Ncayiyana J, Levin J. Health-care utilization and associated factors in Gauteng province. South Africa Glob Health Action. 2017;10:1.

59. Staveteig S, Wang S, Head SK, Bradley SEK, Nybro E. Demographic patterns of HIV testing uptake in sub-Saharan Africa. Calverton, Maryland, USA: ICF International; 2013 [cited 2019 Apr 11]. Report No.: DHS Comparative Reports No. 30. https://dhsprogram.com/publications/publi cation-CR30-Comparative-Reports.cfm. . Accessed 11 Apr 2020.

60. Dessalegn NG, Hailemichael RG, Shewa-amare A, Sawleshwarkar S, Lodebo B, Amberbir A, et al. HIV Disclosure: HIV-positive status disclosure to sexual partners among individuals receiving HIV care in Addis Ababa, Ethiopia. PLoS ONE. 2019;14(2):e0211967.

61. Dominic B. 'Women's Education a Tool of Social Transformation'-A Historical Study Based on Kerala Society. 2011;2(10):7.

62. Corrigan PW. The stigma of disease and disability: Understanding causes and overcoming injustices. Washington D.C.: American Psychological Association; 2014

63. Chanvilay T, Yoshida Y, Reyer JA, Hamajima N. Factors associated with access to antiretroviral therapy among people living with HIV in Vientiane capital, LAO PDR. Nagoya J Med Sci. 2015;77(1-2):29.

\section{Publisher's Note}

Springer Nature remains neutral with regard to jurisdictional claims in published maps and institutional affiliations.
Ready to submit your research? Choose BMC and benefit from:

- fast, convenient online submission

- thorough peer review by experienced researchers in your field

- rapid publication on acceptance

- support for research data, including large and complex data types

- gold Open Access which fosters wider collaboration and increased citations

- maximum visibility for your research: over $100 \mathrm{M}$ website views per year

At BMC, research is always in progress.

Learn more biomedcentral.com/submissions 